\title{
Crescimento e tendência de queda da acumulação de capital no Brasil
}

João Basilio Pereima*

Resumo: As baixas taxas de crescimento econômico do Brasil em 2011 e 2012 e as incertezas quanto à capacidade de crescimento para os próximos anos são sintomas de restrições endógenas da economia brasileira e não apenas resultado de choques exógenos provocados pela crise mundial. As variáveis endógenas representam um conjunto de forças restritivas com impactos muito mais significativos do que o impacto negativo dos choques externos. Estas restrições provêm de mudanças estruturais que estão em curso na economia brasileira, entre as quais se destacam a aproximação rápida do fim do bônus demográfico, limites à expansão do mercado de trabalho e esgotamento da capacidade de absorção de capital (deepening of capital), entre outros fatores conjunturais. Este artigo analisa e dá destaque à três importantes variáveis que podem já estar exercendo um papel restritivo ao crescimento: bônus demográfico, mercado de trabalho e o aprofundamento do capital (deepening of capital), esta última uma ideia que remonta à Harrod Domar (1948), a qual ampliamos o escopo e significado e que é aplicável ao caso do Brasil atual.

Palavras-chave: Crescimento; Acumulação de Capital; Transição Demográfica

Classificação JEL: 010, 040, J11

\footnotetext{
* Doutor em Desenvolvimento Econômico pela Universidade Federal do Paraná (UFPR). Professor adjunto do Departamento de Economia da UFPR e do Programa de Pós-Graduação em Desenvolvimento da UFPR. Vice-Chefe do Departamento de Economia e editor da Revista Economia \& Tecnologia (RET). Endereço eletrônico: joaobasilio@ufpr.br
} 


\section{Introdução}

A taxa de crescimento de $2,73 \%$ em 2011 e a expectativa de crescimento de 1,5\% para 2012 da economia brasileira surpreendeu o país como um todo, em especial o governo. Estas taxas de crescimento estão muito abaixo do crescimento médio de 5,34\%aa observado em 2011 nos demais países da America Latina e abaixo até mesmo de países envoltos com a crise financeira, como EUA, Alemanha e França. Uma das causas explicativas, para este pífio resultado obtido pelo Brasil em 2011 e 2012 é a contaminação das expectativas pelo agravamento da crise na Europa e dificuldades da economia americana. As expectativas negativas estariam colocando um freio nos investimentos privados, temerosos de que um aumento na capacidade produtiva não seria acompanhado por demanda interna suficiente e por dificuldades nas exportações por conta da retração da economia mundial. No entanto este argumento do choque externo deve ser visto com reserva, pois os demais países da América Latina cresceram a taxas elevadas e muito acima da economia brasileira em 2011. No mínimo, tal fato lança no ar a indagação de porque apenas o Brasil estaria sendo afetado pela crise, se é que está? Além do que a própria noção de crise externa precisa ser relativizada uma vez que algumas importantes economias cresceram em 2011 acima de suas taxas médias históricas. Comparando-se os gráficos 1 e 2 a seguir observa-se que a Alemanha, por exemplo, cresceu 3,06\% em 2011, bem acima de sua média histórica de 1,3\%. Os EUA cresceram no mesmo ritmo da sua média história, a França um pouco acima. Apenas o Reino Unido e o Japão apresentaram crescimento menor que o histórico em 2011, sendo que o Japão sofre efeitos locais de catástrofes naturais associadas à diminuição populacional. Este quadro geral põe em cheque a tese da crise externa, até mesmo porque do ponto de vista do crescimento apenas, nem mesmo é possível configurar o ano de 2011 como um ano de recessão mundial, a não ser para alguns países específicos como Reino Unido e em maior extensão Itália e Espanha.

A desaceleração da economia brasileira ocorre na contramão de importantes economias latino americanas e na contramão até mesmo de outras economias desenvolvidas envoltas pela crise. Se considerarmos outras importantes economias como China, Índia, Indonésia, Bangladesh, Paquistão e Turquia, as quais não aparecem no gráfico a seguir, mas que estão crescendo a taxas próximas ou superiores a $6 \%$ aa fica evidente que variáveis locais da economia brasileira estão exercendo restrições ao crescimento, uma vez que um número elevado de países cresceu em 2011 e continua crescendo em 2012 a taxas elevadas, a despeito do que está ocorrendo na Europa e no sistema financeiro dos países desenvolvidos.

As causas do crescimento medíocre da economia brasileira são endógenas. Nas próximas seções do artigo destacamos algumas variáveis importantes que podem ajudar explicar a performance da economia brasileira. Dentre elas destacamos as seguintes: bônus demográfico; mercado de trabalho; aprofundamento do capital (deepning of capital). 


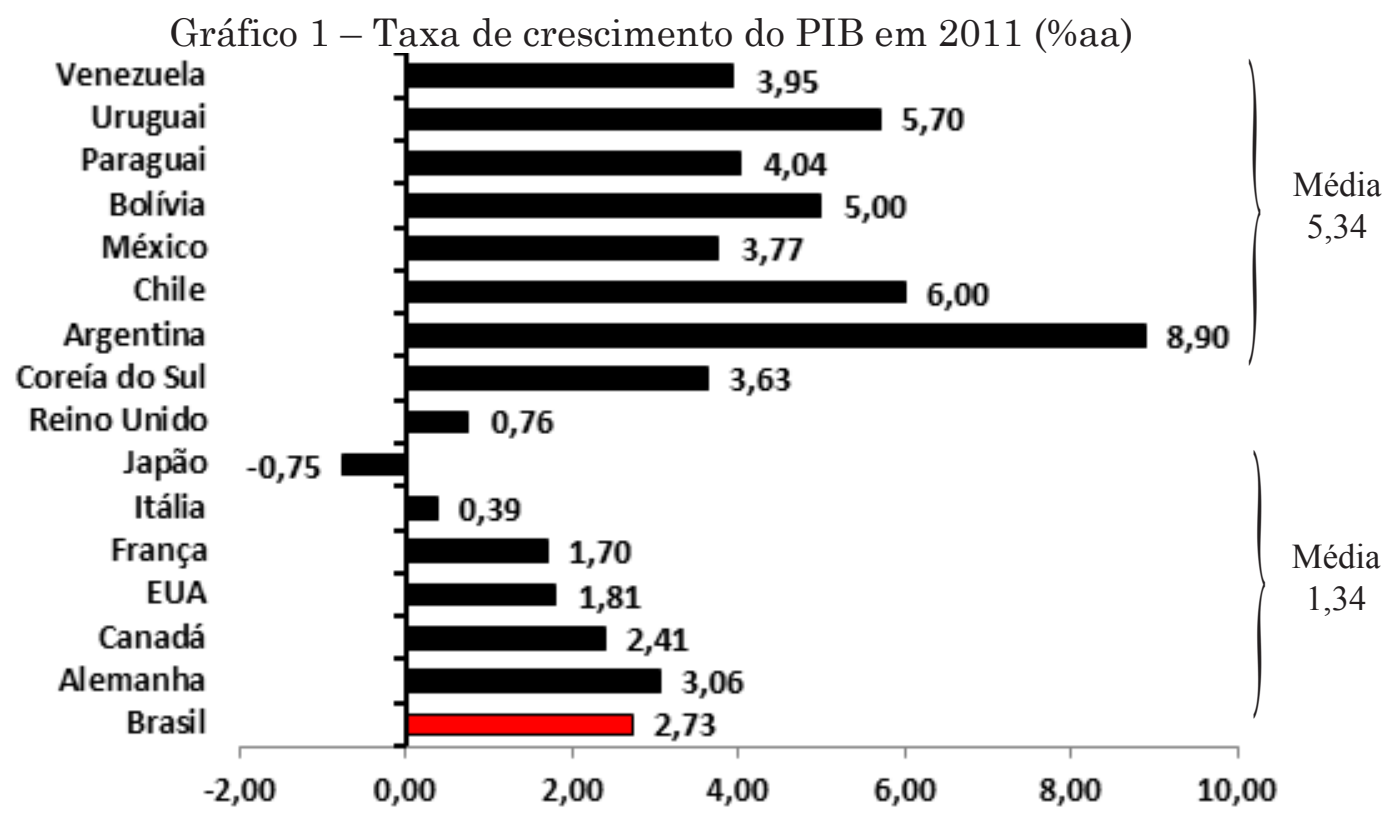

Fonte: Brasil, IBGE, Outros países International Monetary Fund IMF-IFS

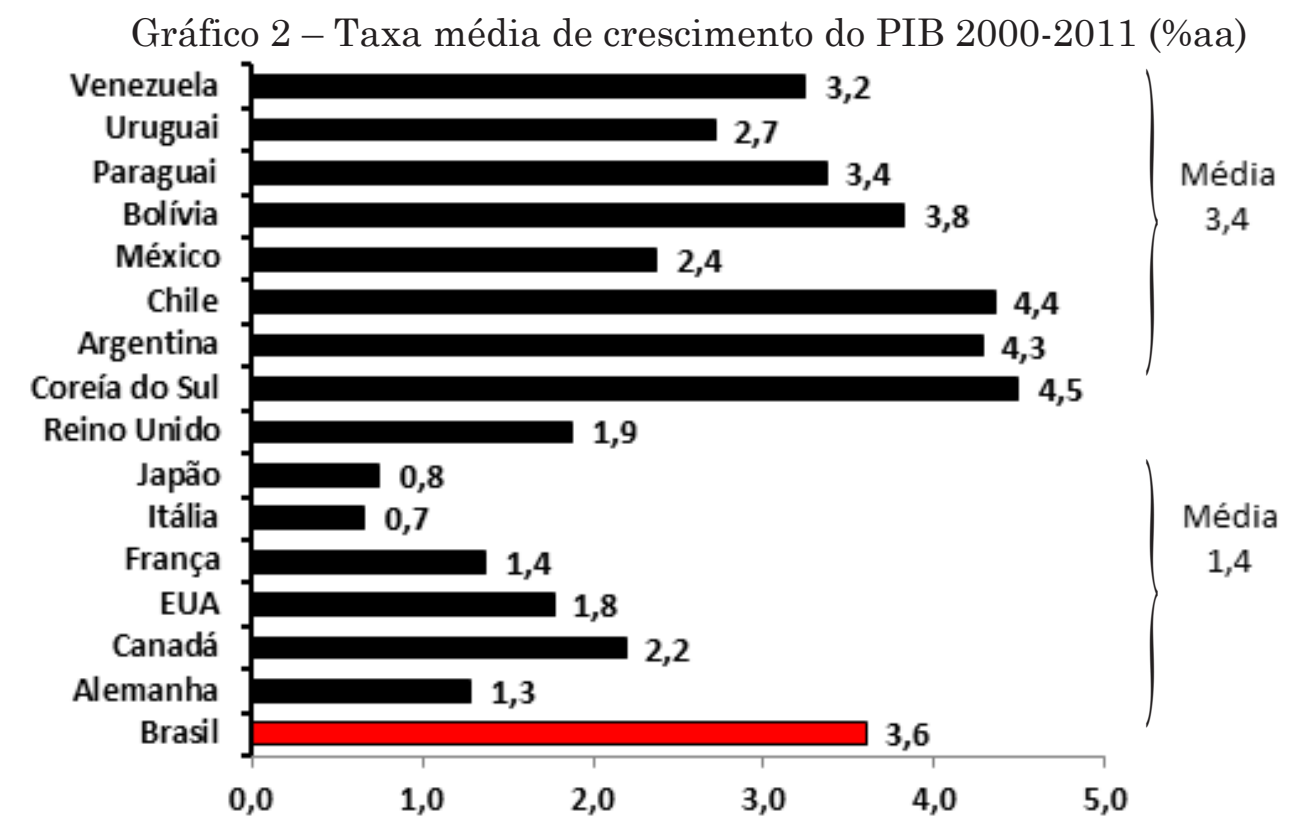

Fonte: Brasil, IBGE, Outros países International Monetary Fund IMF-IFS

\section{Bônus demográfico}

O bônus demográfico, a rigor, é uma variável que atualmente estimula o crescimento da economia brasileira uma vez que está aumentando a população em idade ativa (PIA) como proporção da população total. No entanto mudanças aceleradas no perfil demográfico da população brasileira já começam a se fazer sentir e algumas delas já estão alterando a estrutura do consumo da população e modificando a proporção de pessoas em idade ativa bem como afetando a oferta de mão-de-obra. 
O bônus demográfico teve início no Brasil no ano de 1960 e terminará tecnicamente sessenta anos depois, em 2020, quando a razão de dependência (população jovem e idosa em proporção ao total) começar a subir. Os impactos desta mudança no mercado de trabalho, na renda do trabalho e na distribuição de renda, na formação de poupança, na estrutura do consumo das famílias, no perfil dos gastos públicos e na capacidade de crescimento da economia já estão se fazendo sentir. O Brasil multiplicou sua população por cinco no século XIX e por dez no século XX. Após está explosão demográfica projeções apontam que a população brasileira, mantida a desaceleração atual, começará a diminuir a partir de 2040, quando atingirá o máximo de 219 milhões de habitantes segundo o IBGE ${ }^{1 .}$ A queda na taxa de fecundidade começou já nos anos 1960, alcançou a taxa de reposição de 2,1 filhos por casal em 2005 e continua caindo desde então, até chegar aos atuais 1,8 . As próximas décadas serão marcadas por uma sequência de eventos demográficos que se constituirão em marcos importante na história brasileira. Em 2020 termina o bônus demográfico. Em 2030 a PIA parará de crescer e em 2040 será a vez da população total parar de crescer. Fenômenos assim já atingiram outras nações, como Japão e Alemanha e não é desconhecido no mundo moderno.

A passagem do bônus demográfico pode ser visualizada com a ajuda dos gráficos 3 e 4 a seguir. O bônus demográfico pode ser entendido como o período de tempo em que a população em idade ativa está aumentando em relação à população total. Isto significa dizer que a proporção de pessoas entre 15 a 64 anos de idade está aumentando mais rapidamente que a população jovem, de 00 a 14 anos, e a população idosa, com 65 anos ou mais. O fenômeno recentemente anunciado de que a classe média brasileira atingiu $53 \%$ da população é explicado em grande parte pela mudança demográfica, além, evidentemente, da melhoria recente na distribuição pessoal de renda que elevou a renda das classes $\mathrm{D}$ e E. Mas este bônus demográfico, que já dura 50 anos desde que começou em 1960, está com os dias contados. Terminará em 2020, daqui 8 anos, ou mais dois mandatos presidenciais apenas.

O bônus demográfico pode ser visto com clareza no gráfico 4, onde mostramos a evolução da razão de dependência da população brasileira. A razão de dependência é calculada de três modos, pelo total da população e em seguida desagregada em dependência da população jovem e idosa. O significado da razão de dependência é intuitivo e mostra o percentual da população improdutiva ou dependente, aquela que pelo motivo idade não trabalha e, portanto, não produz, em relação a população total. Uma razão de dependência de $60 \%$, por exemplo, significa que $60 \%$ da população (jovens e idosos) dependem da população economicamente ativa, aquela situada entre 15-64 anos de idade, que será de $40 \%$ do total. Como indicado no gráfico 03, o bônus demográfico é identificado como o período de queda da razão de dependência, que iniciou no Brasil em 1960 e terminará em 2020, quando o mínimo de 43,6\% for atingido. A desagregação por idade mostra também outra mudança demográfica de grande

\footnotetext{
1 De acordo com as projeções das Nações Unidas, por meio da Population Division, a população máxima será de 224 milhões de habitantes, na mesma data. As projeções seculares levam em conta, obviamente, a tendência atual e não incluem mudanças, difíceis de prever, nas taxas de natalidade nas próximas décadas, especialmente pós 2050.
} 
significado social e econômico. A dependência populacional cai dramaticamente na população jovem e aumenta na população idosa.

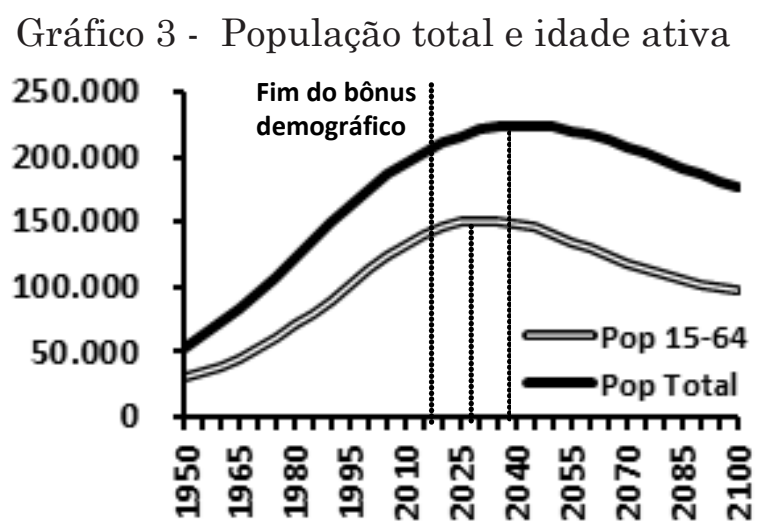

\section{Gráfico 4 - Razão de Dependência}

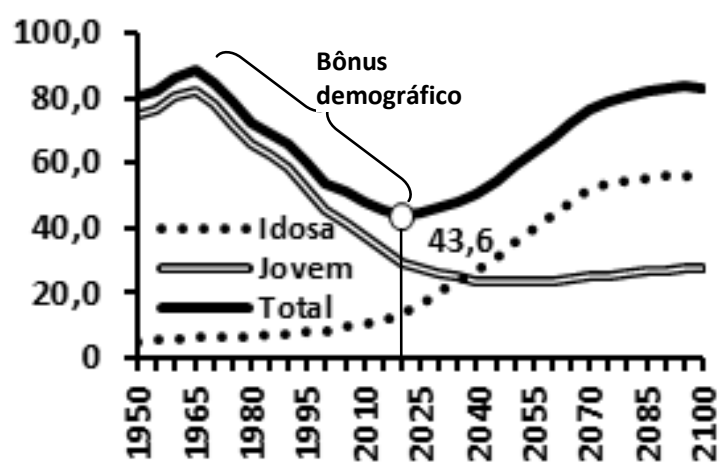

Fonte: IBGE, United Nations, Department of Economic and Social Affairs: Population Division, Population Estimates and Projections Section: http://esa.un.org/wpp/Excel-Data/population. htm. Mudanças demográficas pós 2010: projeções com base no cenário médio.

Os impactos da passagem do bônus demográfico, e do seu fim, são enormes, porém seus efeitos quantitativos sobre as taxas de crescimento são desconhecidos no Brasil. Estudos realizados em outras economias indicam que há uma forte relação entre bônus demográfico com consumo e poupança agregada bem como uma estreita relação entre crescimento econômico e mudança populacional, por meio de vários canais.

A teoria econômica prevê, quando a proporção de população adulta em relação à população total é alta, uma expansão no investimento em bens de capital necessários para acomodar os entrantes no mercado de trabalho, e uma expansão na oferta de residência para as novas famílias (Abramovitz, 1961; Easterlin, 1968).

Do ponto de vista do mercado de trabalho a teoria prevê que uma queda da razão de dependência (pelo aumento da população em idade ativa) pode contribuir para um aumento do produto per capita, especialmente quando houver um adensamento populacional e possibilidades de obtenção de rendimentos crescentes oriundos da aglomeração. Durante o período de queda da razão de dependência, particularmente em razão de elevada taxa de fecundidade, haverá um oferta abundante de mão de obra com efeitos adversos no sistema econômico. O excedente de mão de obra mantém os salários baixos e os lucros altos e impulsiona com isso os investimentos. No entanto, aciona um mecanismo de concentração de renda que retira poder de compra dos trabalhadores e da classe média em geral.

Os impactos da mudança demográfica sobre a demanda de bens e serviços podem ser analisados a partir da teoria do ciclo de vida do consumo de Franco Modigliani e Richard Brumberg (1954) e a extensão implementada por Albert Ando e Modigliani (1963). Segundo esta teoria as pessoas em seus primeiros anos de trabalho consomem uma fração menor de sua renda corrente do que 
pessoas mais jovens e mais velhas. Testes empíricos realizados posteriormente comprovaram este comportamento do consumo. Fair e Domingues (1991) estimaram os coeficientes de consumo de serviços, bens não duráveis, duráveis e aquisição de residências a partir da renda para diferentes idades para economia americana. Em todos os casos encontram uma relação não linear entre 15 e 70 anos tal que, na idade mais jovem a propensão à consumir é alta, diminui durante a idade principal de trabalho e volta a subir entre os mais idosos, com o ponto de mínimo situado em torno dos 50 anos no caso de bens duráveis e 35 a 40 nos demais tipos de bens e serviços. Ou seja, a capacidade máxima de poupança e investimento, e portanto, de crescimento é atingida quando a maior parte da população tiver idade entre 35 e 40 anos.

Outro canal por onde a mudança populacional impacta o crescimento são as finanças públicas (Alesina e Perotti, 1994). Durante a fase de maior crescimento econômico associado a maior participação da população em idade ativa também significa simultaneamente receitas fiscais maiores e mais poupança pública e necessidade de menor gasto social com populações jovens e idosas. Menor é a dependência de políticas públicas compensatórias e de promoção de bem estar uma vez que a maior parte da população está em idade ativa a qual, se encontrar demanda suficiente de mão de obra no mercado, fato que acontecerá 'naturalmente' se a economia estiver crescendo, dependerá menos do governo.

A década de 2010, já iniciada, será marcada pelo fim do bônus demográfico e pelo fim da contribuição do crescimento populacional ao crescimento econômico.

\section{Mercado de Trabalho e Restrições de Oferta de MO}

O ciclo de crescimento recente da economia brasileira iniciado em 2004, em conjunto com a queda da taxa de fecundidade que vem sendo observada desde 1960, fez a taxa de desemprego cair para seu menor valor histórico em 2012, pressionando os salários para cima. Embora parte significativa da queda do desemprego dos últimos anos deva ser atribuída ao crescimento econômico puxado pela demanda, uma parcela significativa desta performance deve também ser atribuída à um fenômeno demográfico mostrado acima.

Os ciclos de crescimento brasileiro desde o início de seu processo de industrialização podem ser classificados como processos de crescimento baseado predominantemente em acumulação de capital. A contribuição da produtividade total dos fatores no Brasil, bem como no restante da América Latina, tem sido baixa em comparação com as economias desenvolvidas (Cole et al, 2005; Ferreira, 2012). A acumulação de capital no Brasil sempre foi viabilizada pela oferta abundante, "ilimitada", de mão de obra, de modo que o aumento de produção sempre pode ser acompanhado pelo aumento no número de horas trabalhadas sem causar-lhes maiores embaraços ou restrições. Não encontrando restrições fortes pelo lado da oferta, por falta disponibilidades de fatores de produção, o Brasil pode crescer a taxas elevadas, sendo o ápice deste processo o período de 1975-1979 do II Plano Nacional de Desenvolvimento. 
Problemas macroeconômicos do endividamento externo, restrições no balanço de pagamento e inflação durante as décadas de 1980 e 1990 restringiram as tentativas e a capacidade de fazer crescer a renda per capita da economia neste período.

A queda recente da taxa de desemprego e da taxa de crescimento da população ativa estão começando a inverter o quadro no mercado de trabalho o qual está se tornando uma restrição ao crescimento baseado em acumulação de capital. Dados agregados acumulados ao longo das últimas duas décadas mostram que enquanto a população cresceu $28,6 \%$ ao longo de duas décadas, entre 1992 e 2011, a população em idade ativa e o pessoal ocupado cresceram $46.8 \%$ e 48,9\% respectivamente. O crescimento acumulado do PIB de $86,3 \%$ foi possível graças ao excedente de mão de obra disponível na economia.

\begin{tabular}{lr} 
Tabela 1 - Taxa Acumulada de crescimento - & 1992-2011 \\
\hline \multicolumn{1}{c}{ Variável } & Acum \\
\hline População & 28,6 \\
População em Idade Ativa 1 & 46,8 \\
Pessoal Ocupado nas Regiões Metropolitanas & 48,9 \\
PIB & 86,3 \\
\hline Fonte: Elaborado a partir de dados do IBGE. \\
Nota: (1) População em Idade Ativa (PIA), pessoas com 10 \\
anos ou mais de idade.
\end{tabular}

Os sinais de esgotamento da oferta de mão obra em setores e regiões já são visíveis e eles não são fenômenos conjunturais. A tabela 2 mostra uma estimativa de saldo entre oferta e demanda de mão-de-obra realizada em 2011 para o final deste mesmo ano mostra escassez de mão-de-obra em setores chaves da economia. Os menores saldos são observados exatamente nos setores mais dependente de mão de obra qualificada: indústria; Educ, saúde, serv. soc.; Comércio e reparação; Transp, armaz, comun..

Tabela 2 - Estimativa de saldo entre oferta e demanda

de mão de obra em 2011 por grandes regiões geográficas

\begin{tabular}{l|rrrrrr}
\hline \multirow{2}{*}{ Atividade } & \multicolumn{6}{c}{ Região } \\
\cline { 2 - 7 } & \multicolumn{1}{c}{ Norte } & Nordeste & Sudeste & \multicolumn{1}{c}{ Sul } & Centro- & \multicolumn{1}{c}{ Orasile } \\
\hline Administração pública & 10.576 & 22.364 & 15.521 & 12.581 & 10.744 & 71.786 \\
Agrícola & 1.454 & 46.227 & 78.257 & 11.638 & 12.946 & 150.522 \\
Alojamento e aliment. & -254 & 26.737 & 21.640 & 1.930 & 10.632 & 60.685 \\
Comércio e reparação & 22.319 & 81.245 & -82.997 & -660 & 30.377 & 50.283 \\
Construção & 15.287 & 16.612 & 9.518 & 9.743 & 16.176 & 67.336 \\
Educ, saúde, serv. soc. & 2.238 & 799 & 18.325 & 13.684 & 5.278 & 40.324 \\
Indústria & 10.811 & 25.849 & -15.013 & -51.590 & -4.556 & -34.499 \\
Outros serviços & 47.112 & 171.636 & 251.141 & 60.944 & 60.238 & 591.071 \\
Transp, armaz, comun & 1.605 & 13.577 & 32.140 & -2.860 & 6.807 & 51.270 \\
\hline Total & 11.149 & 405.046 & 328.534 & 55.410 & 148.640 & 1.048 .779 \\
\hline
\end{tabular}

Fonte: IPEA, 2011. 
Tabela 3 - Pesquisa Mensal do Emprego - (Estimativa 2012)

\begin{tabular}{lrrr}
\hline \multicolumn{1}{c}{ Especificação } & ago/11 & ago/12 & Var \\
Absol. \\
\hline Pessoas em Idade Ativa & 41.964 & 42.495 & 531 \\
Pessoas Economicamente Ativas & 24.064 & 24.239 & 175 \\
Pessoas Ocupadas & 22.623 & 22.952 & 329 \\
Pessoas Desocupadas & 1.440 & 1.287 & -153 \\
Taxa de Ocupação & 94,0 & 94,7 & \\
Taxa de Desocupação & 6,0 & 5,3 & \\
\hline Economicamente Ativas (Taxa de Atividade) & 57,3 & 57,0 & \\
Ocupadas & 53,9 & 54,0 & \\
Desocupadas & 3,4 & 3,0 & \\
Não Economicamente Ativas & 42,7 & 43,0 & \\
\hline
\end{tabular}
Fonte: IBGE, PME

Se tomarmos o saldo atual entre oferta e demanda em 2012 como sendo aproximadamente o mesmo de 2011, então podemos constatar que há uma demanda excedente de 1.048.779 trabalhadores (tabela 2) ao passo que há 1.440.000 pessoas desocupadas (tabela 3). A taxa de ocupação está em 94,7\% em 2012. Este estoque de mão de obra é facilmente exaurível com dois ou três anos de crescimento econômico acima de 3,5\%. Resta como fonte "potencial" de oferta mão de obra parte da população em idade ativa que não esta ofertando mão de obra, a qual é de 41.964.000 pessoas, contra uma população de efetivamente está ofertando mão de obra, de 24.064.000 (tabela 3), de acordo com os critérios usados para calcular a oferta de mão de obra. Isto dá uma taxa de atividade (PEA/ PIA) de 53,7\%. Resta saber se este saldo remanescente satisfaz as exigências do mercado de trabalho quanto à qualificação e anos de estudo.

As mudanças na estrutura da mão de obra, que se manifestam nos números acima, estão fortemente correlacionadas com a transição demográfica. Como pode ser observada na tabela (4), a composição etária mudou significativamente desde março de $2002^{2}$.

Tabela 4 - Pessoal Ocupado na semana de referência por idade Variação entre março/2002 set/2012

\begin{tabular}{lr}
\hline \multicolumn{1}{c}{ Grupo Etário } & \multicolumn{1}{c}{ Var \% } \\
\hline 10 a 14 anos & $-65,48$ \\
15 a 17 anos & $-16,13$ \\
18 a 24 anos & 2,53 \\
25 a 49 anos & 28,71 \\
50 anos ou mais & 96,05 \\
\hline Total & 32,85 \\
\hline Cresc. da população & $12,5 \%$ \\
\hline Fonte: IBGE PME
\end{tabular}

O aumento significativo de mão de obra ocupada tem se situado em faixa etária acima de 24 anos e em especial acima de 50. O número de pessoal ocupado entre 25 e 49 subiu 28,\% desde março de 2002, e acima de 50 anos

2 De acordo com a nova metodologia da Pesquisa Mensal do Emprego (IBGE) usada a partir desta data. 
subiu incríveis $96 \%$, sendo que a população cresceu apenas $12,5 \%$ neste período. Igualmente interessante é a queda intensa do pessoal ocupado nas faixas etárias jovens. Estes dados coincidem com a transição demográfica e o envelhecimento da população.

Tabela 5 - Pessoal Ocupado por anos de estudo Variação entre março/2002 e ago/2012

\begin{tabular}{lr}
\hline \multicolumn{1}{c}{ Anos de Estudo } & Var \% \\
\hline Sem instrução e menos de 1 ano & $-40,5$ \\
1 a 3 anos & $-40,1$ \\
4 a 7 anos & $-13,7$ \\
8 a 10 anos & 11,6 \\
11 anos ou mais & 86,2 \\
\hline Total & 33,0 \\
\hline Fonte: IBGE, PME
\end{tabular}

A questão mais intrigante e importante são as implicações das transformações no mercado de trabalho para o crescimento futuro da economia. O processo de crescimento econômico, baseado em acumulação mais que inovação, depende essencialmente da disponibilidade de expansão dos fatores de produção e no caso da disponibilidade de mão-de-obra. Se é correto que a "taxa natural de crescimento" por acumulação de capital, tal como estabelece a teoria do crescimento, é igual à taxa de crescimento da população em idade ativa, então a taxa natural de crescimento da economia brasileira é de apenas 1,3\%aa e em queda. A obtenção de uma taxa de crescimento acima de 1,3\% somente será possível se houver aumentos de produtividade ou se a economia usar outras formas de capital, como é o caso do capital humano, que é uma forma de separar a tradicional oferta de horas de trabalho, por uma medida diferenciada de mão-de-obra baseadas em tempo de estudo. Isso requer políticas educacionais mais agressivas que já deveriam ter sido adotadas no passado e não foram. A oferta de mão de obra com maior nível educacional para atender a demanda de uma economia intensiva em tecnologia provém da nova geração e não da geração com idade acima de 50 anos (tab 4). A demanda por maior grau de educação pode ser observada na tabela 5 , que combinada com as informações da tabela 4 mostram uma situação desfavorável: considerando que a população de 50 anos acima dificilmente está se educando, especialmente nas universidades, e que a demanda no mercado de trabalho privilegia 11 ou mais anos de estudo, então a fonte imediata de mão de obra seria a população jovem, que em termos demográfico está diminuindo em proporção à população total.

A restrição da mão-de-obra ao crescimento econômico, baseado em acumulação ou aprofundamento do capital, está cada vez mais forte.

\section{Aprofundamento do capital (deepning of capital)}

A noção de aprofundamento de capital (deeping of capital) foi aventada 
em 1948 por Harrod Domar, ao tratar dos limites do crescimento econômico, numa época que as teorias do crescimento, estavam apenas começando a ser construídas. Comentando sobre as preocupações que estavam surgindo à época, após um período de elevado crescimento da oferta e da demanda com seus efeitos inflacionários, e sobre as dúvidas quanto a capacidade de continuar crescendo por acumulação de capital, Domar (1948, p. 777) expressou-se do seguinte modo:

Implicit in this worry is the belief that the possibilities of the so-called deepening of capital (in the sense of an increasing ratio of capital to output) are limited. Therefore the amount of capital that the economy can absorb, at a given income level and over a given period of time, is limited as well. The more rapidly it accumulates, the sooner investment opportunities are exhausted and a depression ensues. [Grifo adicionado]

No sentido restrito de Domar, o aprofundamento do capital vai até o ponto em que o efeito demanda do investimento é capaz de absorver a expansão da oferta, via efeito capacidade do mesmo investimento. Mas podemos atribuir um sentido mais amplo ao termo aprofundamento do capital e incluir o esgotamento das oportunidades de investimento (leia-se acumulação de capital) pelo desenvolvimento econômico à medida que este preenche as necessidades de consumo da população bem como a necessidade de infra-estrutura, tal como já ocorre nos países industrializados. Nestes países o saldo de moradias, a oferta de bens de consumo duráveis e de infraestrutura como construção de estradas, aeroportos, usinas de energia, etc, suprem as necessidades da sociedade, de forma que as oportunidades para novos projetos de investimento é muito baixa. Nestes países a principal fonte de crescimento é a produtividade e mais ainda as inovações radicais que, num processo de criação mais que destruição, adicionam novas necessidades e absorvem parte da elevada renda per capita. O oposto ocorre em países em desenvolvimento em que a carência de bens de consumo e infraestrutura é grande o suficiente para garantir as oportunidades de acumulação de capital e trabalho. No período de transição ou mudança estrutural, os países em desenvolvimento vão progressivamente aprofundando seu capital. Durante o período de industrialização forçada do Brasil na década de 1970, a construção de uma grande geradora de energia hídrica como Itaipu tinha um impacto tremendo na taxa de crescimento da economia, dado o gigantismo relativo da obra em relação ao tamanho da economia. Hoje um investimento do mesmo porte como será a usina de Belo Monte, terá um impacto relativo muito menor.

Do ponto de vista da acumulação de capital a principal fonte de expansão da economia é o aumento do estoque de capital físico, o qual inclui tanto máquinas e equipamentos em geral, edificações, quanto infraestrutura. Tudo reunido e dada uma tecnologia constante, a ampliação do estoque de capital físico requer uma quantidade de mão de obra proporcional para operar o capital, na forma de uma relação capital-trabalho fixa. É possível, se assumirmos que trabalho e capital possam ser substituíveis, que alguma taxa extra de crescimento por expansão 
do capital físico possa ser obtida fazendo com que o estoque de capital aumente mais que proporcionalmente ao trabalho, o que requer troca ou aperfeiçoamento de tecnologia de produção. Um longo debate na teoria econômica, em torno da chamada "controvérsia do capital" colocou em lados opostos alguns economistas: os que acreditam que capital e trabalho são fatores insubstituíveis e que não é possível especificar uma função de produção para uma economia como um todo, em função das dificuldades para agregar os mais diferentes tipos de bens de capital, desde uma enxada até um satélite em órbita; e os que acreditam que é possível fazer isso, mesmo que de forma aproximada e que é muito mais útil e simples usar uma função de produção agregada, com todos seus problemas, do que as outras alternativas ${ }^{3}$.

Seja qual for o angulo de ataque ao problema, com ou sem função de produção, para efeitos de crescimento econômico baseado em acumulação de capital o que importa discernir é a capacidade da economia em aumentar o estoque de capital físico e a quantidade de trabalho contratada sujeita à algumas restrições: a restrição imposta pela oferta de mão-de-obra, uma vez que se assuma que a substituibilidade de capital por trabalho é restrita; a restrição imposta pelas relações setoriais, e as restrições impostas pelo aprofundamento do capital no sentido amplo. A restrição da oferta de mão-de-obra decorre do processo demográfico em curso. A restrição setorial significa que a quantidade de capital físico entre diferentes setores se complementam de tal forma que o tamanho de um, está relacionado ao tamanho do outro e somente no longo, longo prazo pode sofrer alterações profundas (mudança estrutural). Apenas a mudança tecnologia é capaz de alterar estas três restrições, e isso só acontece lentamente.

Por fim a terceira e última é a restrição pelo aprofundamento do capital no sentido estrito de Domar e no sentido amplo que inclui necessidades de consumo, residências e infraestrutura em geral. Tal restrição é facil de observar tomandose as condições do lado da oferta da economia, em que se tomam as decisões de investimento (acumulação de capital) e gastos em pesquisa e desenvolvimento. A restrição que pode acontecer ao processo de crescimento baseado na acumulação de capital é o fato de que o crescimento econômico puxado pela demanda tende a não alterar as relações entre $Y / K$ (produtividade do capital) e $Y / N$ (produtividade da mão-de-obra), uma vez que o impulso básico é no sentido de explorar os recursos existentes. Uma vez esgotados o saldo de mão de obra desocupada e as possibilidades de aprofundamento do capital, o crescimento da renda per capita apenas seria possível mediante progresso tecnológico na forma de produtividade (aumento de $Y / N$ ) ou através de inovações radicais criadoras de ondas ao estilo de Schumpeter (1934). O fato estilizado de que a origem da maior parte das inovações se localizarem em países ricos, não se explica apenas pelo lado da renda e poder aquisitivo, mas também porque nestas sociedades as oportunidades de investimento e acumulação de capital chegaram próximo do

3 Sraffa, por exemplo, chegou a afirmar que "o produto marginal de um fator seria não apenas difícil de encontrar, ele simplesmente não existe para ser achado" (Sraffa, p. V). No outro extremo, Samuelson (1962, p. 164) adotava uma postura diferente, propondo-se "mostrar como podemos algumas vezes predizer exatamente como alguns modelos de capital heterogêneos bastante complicados vão comportar-se tratando-os como se eles tivessem vindo de uma simples função de produção geradora". No mínimo as funções de produção agregadas são uma metáfora útil. 
seu limite antes que as demais economias, carentes de tudo. Resta-lhes como alternativa ao crescimento da renda per capita intensificar a produtividade e a busca por novos produtos e processos, com introdução de novas tecnologias.

A restrição ao aprofundamento de capital pode ser atenuada, mas não completamente eliminada pela chamada "Lei" de Kaldor-Verdoorn, segundo a qual a produtividade do setor de manufaturas e do restante da economia é uma consequência do crescimento quantitativo do próprio setor de manufaturas, setor intensivo em tecnologia (Verdoorn, 1949; Kaldor, 1966, 1975). Segundo seus defensores é possível que um aumento da demanda de bens duráveis (ou manufaturados em geral) possa exercer um efeito positivo na produtividade deste e dos demais setores. O processo pode ser desmembrado em três efeitos: o primeiro leva em conta o fato de que o crescimento agregado da economia está correlacionado com a taxa de crescimento do setor de manufaturas, para além da relação espúria entre os dois; o segundo efeito considera que um aumento na taxa de crescimento das manufaturas conduz à um aumento da produtividade e dos salários do próprio setor, que é a "lei" da Kaldor-Verdoorn propriamente dita; e por fim o terceiro efeito considera que o aumento da produtividade das manufaturas transborda para a produtividade dos demais setores. A principal mensagem da ideia de Kaldor-Verdoorn é que o retorno crescente de escala do setor de manufaturas transborda sua margem e impulsiona o crescimento da produtividade e da renda per capita dos demais setores e da economia como um todo. Isto pode ser visto com um argumento para a existência de retornos crescentes de escala que ocorre mais intensivamente na indústria devido à learning by doing e outras formas de mudança tecnológica. Um estudo de Mamgain (1999) aponta para a validade inconteste da "Lei" de KaldorVerdoorn na Coréia do Sul, nos mini-dragões Indonéia, Tailândia e Maurituis a lei é observada mas com menos força, e nos casos de Malásia e Singapura as evidências são fracas. Nassif et al (2012) encontram evidências fortes para o caso do Brasil e Harris e Lau (1998), por sua vez, testaram a validade da "lei" Kaldor-Verdoorn para o Reino Unido no período 1968-1991 e concluíram pela não validade da "lei". Tais evidências empíricas podem estar sugerindo que a "lei" seja importante para países em desenvolvimento, mas não para países desenvolvidos cujo setor industrial já atingiu sua maturidade. Portanto, parece que o estágio de desenvolvimento importa para os resultados. Em termos de nossa classificação das restrições ao aprofundamento de capital, nos países desenvolvidos ou industrializados a composição setorial da economia como todo não suportaria um maior peso para as manufaturas, a não ser que fossem orientadas para exportação, de forma que não haveria espaço para explorar os ganhos de produtividade via "lei” de Kaldor-Verdoorn.

Assim sendo, para efeito de avaliar a capacidade de crescimento de uma economia, interessa saber, ao lado das restrições da oferta de mão de obra ${ }^{4}$, até onde foi o aprofundamento do capital numa economia, tanto em termos setoriais (peso relativo da indústria ou manufatura), quanto em termos de satisfação das necessidades de consumo de bens duráveis, residências e infraestrutura.

4 Tal como estudas na seção 3 "Mercado de Trabalho e Restrições de Oferta de MO". 
Conforme pode ser observado na tabela (5a) o crescimento da economia brasileira desde 1950 até 2005 tem se beneficiado predominantemente da acumulação de capital $(K / L)$ e trabalho $(L / N)$ e em pequena monta da produtividade total dos fatores $(P T F)$. Mesmo nos períodos em que a PTF foi alta para os padrões brasileiros (década de 1950 e década de 1970) a contribuição dos demais fatores, capital e trabalho, foi muito maior. Comparado à uma pequena amostra de outros países, o Brasil obteve uma taxa média de crescimento no período 1970-2003 de 1,78\%aa, fruto basicamente de acumulação de capital e mão de obra. A contribuição da PTF foi de pífio 0,19pp, número apenas superior à Argentina e México que tiveram PTF negativas (tabela 5b), e muito abaixo de países líderes de forma a configurar uma situação de falling behind ao invés de catching-up, o que é preocupante.

Tabela 5 - Produtividade Total dos Fatores no Brasil e outros países \%aa*

\begin{tabular}{|c|c|c|c|c|c|c|c|c|c|}
\hline \multicolumn{5}{|c|}{ a) Brasil } & \multicolumn{5}{|c|}{ b) Países - 1970-2003 } \\
\hline Brasil & PIB & PTF & $\mathrm{K} / \mathrm{L}$ & $\mathrm{L} / \mathrm{N}$ & & PIB & PTF & $\mathrm{K} / \mathrm{Y}$ & $\mathrm{L} / \mathrm{N}$ \\
\hline $1950-59$ & 4.00 & 1.45 & 2.54 & 0.02 & Argentina & 0.11 & -0.85 & 0.75 & 0.22 \\
\hline $1960-69$ & 2.74 & 0.66 & 1.25 & 0.82 & Brasil & 1.78 & 0.19 & 0.75 & 0.83 \\
\hline $1970-79$ & 5.66 & 1.31 & 1.85 & 2.43 & Chile & 2.08 & 1.47 & -0.30 & 0.90 \\
\hline $1980-89$ & 0.07 & -1.59 & 0.00 & 1.69 & México & 1.33 & -0.49 & 0.70 & 1.12 \\
\hline 1990-99 & 0.70 & 1.01 & 0.53 & -0.83 & EUA & 2.14 & 0.98 & 0.58 & 0.57 \\
\hline $2000-05$ & 1.30 & 0.69 & -0.18 & 0.78 & Coréia & 6.03 & 2.98 & 1.78 & 1.15 \\
\hline
\end{tabular}

O caso da Coréia é educativo: quase metade da sua elevada taxa de crescimento de 6,03\%aa deve-se ao aumento de produtividade dos fatores, o qual ocorreu simultâneamente à absorção de mão de obra e ao aprofundamento de capital. No estudo de Mangaim (1999, p. 301) o coeficiente de sensibilidade da produtividade do setor de manufaturas em relação à taxa de crescimento da produção deste setor, o qual mede a "lei" de Kaldor-Verdoorn, foi de 0,52 (eq. 11), sugerindo que a Coréia soube aproveitar as relações macroeconômicas embutidas nesta lei. Os resultados medidos por PTF revela que a Coréia fez muito bem a lição de casa, combinando aumento de produtividade com aprofundamento de capital e uso mão de obra. No caso brasileiro Nassif et al (2012, p. 34, tab. 4) encontraram um coeficiente de 0,52 para o período 1990-2010. Apesar da semelhança do coeficiente de Kaldor-Verdoorn, é gritante a diferença na taxa de crescimento da produtividade, quando medida pela PTF, um fenômeno que precisa ainda ser explicado, e cuja tarefa está além dos nossos objetivos atuais. Uma resposta possível ao problema está relacionado ao regime de crescimento de cada país e ao fato de que o Brasil até 2009, não exauriu completamente suas oportunidades de aprofundamento de capital. Na falta de uma medida precisa sobre o grau de aprofundamento de capital, ou alguma medida de necessidade de bens de consumo, residência e infraestrutura, podemos usar como proxy a taxa 
de investimento como proporção do PIB. Uma vez que o investimento constitui formação bruta de capital fixo, um longo período de altas taxas de investimento, além do tradicional efeito sobre a acumulação de capital também significa que o país está se aproximando do seu limite de aprofundamento do capital e que dai para frente cessa ou diminui o crescimento por acumulação de capital e tem início uma fase de crescimento baseado em produtividade e inovação. A evolução da taxa de investimento para alguns países selecionados é mostrada no gráfico 4 a seguir. As escalas dos gráficos estão padronizadas e uma linha de referência no nível de $25 \%$ foi adicionada para todos os países.

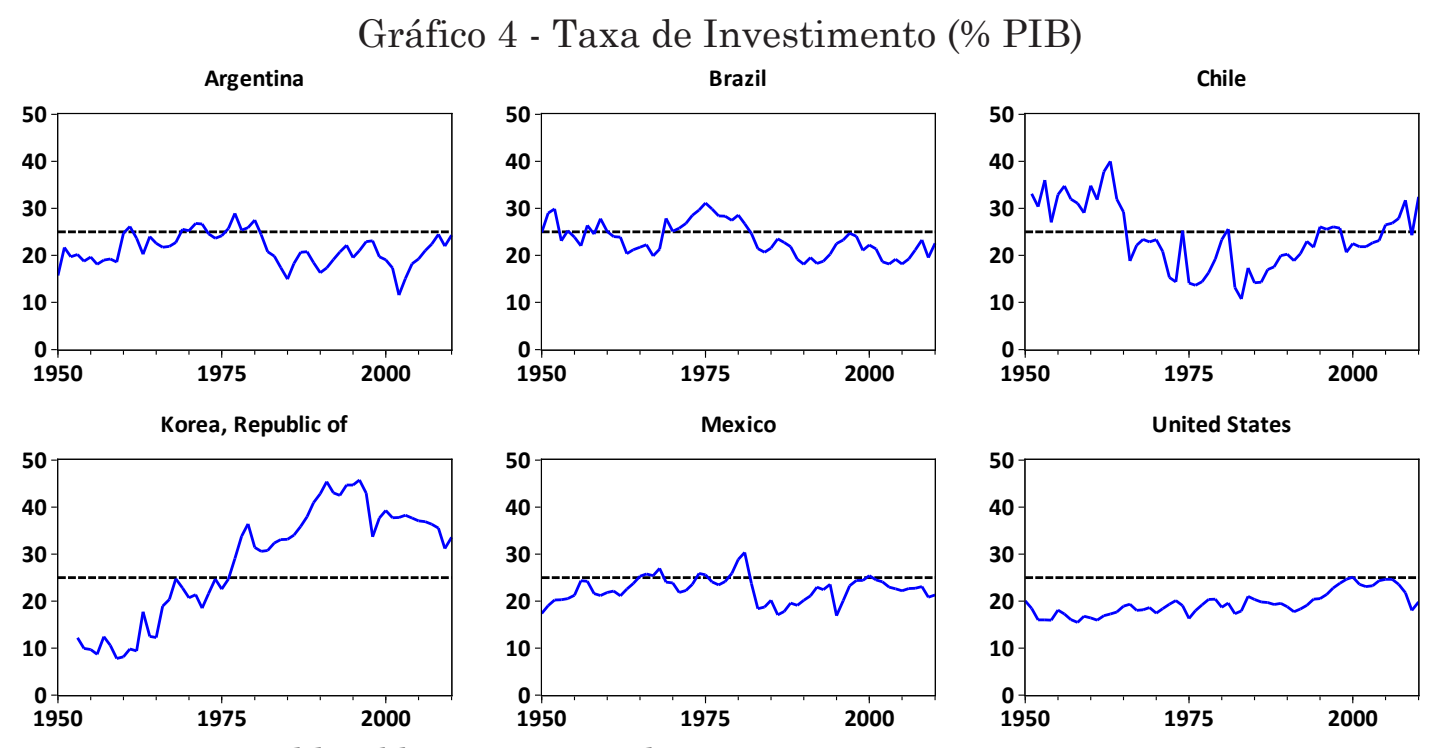

Fonte: Penn World Tables PWT 7.1, july-2012.

Comparando-se o caso da Coréia com o do Brasil é nítida as diferenças na taxa de investimento da cada um. A alta taxa da Coréia em todo o período, especialmente a partir dos anos 1970, atingiu o pico em 1995 e desde então vem caindo de forma gradativa. Poderia a desaceleração dos investimentos, (acumulação de capital) configurar uma situação de exaustão ao aprofundamento de capital? Acreditamos que sim, muito embora a Coréia seja uma economia exportadora que tem no mercado mundial uma fonte de expansão muito grande, o que pode afastar um pouco a fronteira de oportunidades. A taxa de investimentos do Brasil desde os anos 1980 tem ficado sistematicamente abaixo dos $25 \%$, com o que o país ainda apresenta um amplo espaço de aprofundamento do capital, embora algumas restrições já estejam começando a se manifestar. Uma delas vem do lado do mercado de trabalho, como já dito, e a outra do lado do próprio capital a qual aos poucos vai atingindo seu nível máximo a medida que a infra-estrutura faltante for sendo construída nos próximos anos.

No passado, as oportunidades de crescimento por acumulação de capital no Brasil eram muito maiores e justificava a concentração nas estratégias de crescimento por acumulação de capital como forma de constituir uma indústria interna. Conseguir uma taxa de investimento da ordem de $25 \%$ no atual estágio de desenvolvimento é muito difícil no Brasil, quanto mais atingir os valores 
históricos passados de 30\% quando o processo de industrialização estava em curso. O problema não é tanto a mobilização de poupança como condição prévia para existência de investimento, a qual aliás, é endógena uma vez que a existência de crédito cria a poupança necessária na forma de um tipo de poupança fiduciária como ocorre com a moeda, mas sim de oportunidades de investir em mercados desenvolvidos e abastecidos. Este é um segundo e importante vetor de força que faz com que a taxa de investimento caixa em estágios mais avançados de desenvolvimento. Aconteceu isso na Coréia e está acontecendo isso na China, com a desaceleração do seu crescimento nos últimos dois anos. Ao longo do processo de mudança estrutural vivido pelas economias em transição em algum momento o crescimento da renda per capita deixa de depender da acumulação de capital e passa a depender da produtividade e inovação.

\section{Considerações Finais}

Hoje o país se debate em torno da restauração do crescimento econômico perdido em 2011 e 2012. As medidas até o momento adotas são paliativos e arremedos de curto prazo que procuram restabelecer a demanda em tempos de crise. Não estão errados se o objetivo for apenas este. Queda de taxas de juros e redução temporária de impostos tem sido as duas principais ferramentas. Isto funciona na crise, mas não resolve o problema estrutural que é produtividade e inovação. Até dois anos atrás não se falava em pleno emprego no Brasil e ainda hoje muitos se recusam a pensar o crescimento brasileiro num cenário de pleno emprego. Se é fato que o país ainda não esgotou sua oferta de mãode-obra, também é fato que a taxa de atividade (PO/PEA) está em 94,7\%. A capacidade de produção de alguns setores (automobilístico e linha branca por exemplo) é maior que a demanda e portanto os investimentos ou a acumulação de capital que ocorrerem nestes setores são relativamente insignificantes em relação ao tamanho total da economia medido pelo PIB. Apesar da carência de infraestrutura, também é fato que a infraestrutura faltante poderá ser construída e exaurida em mais um ciclo de acumulação de capital, que é a ideia motriz do Programa de Aceleração do Crescimento (PAC). Em se esgotando tal carência nos próximos 5 a 7 anos, qual será o novo sustentáculo para aumento da renda per capita?

O país chegou à um estágio de desenvolvimento econômico caracterizado por um nível baixo de renda per capita em relação a outros países, e não conseguiu diminuir a diferença (catching up) nos últimos anos. Juntamente a isso aproxima-se do fim do estágio de crescimento intensivo em acumulação de capital com um déficit enorme de capital humano e competitividade tecnológica, de forma que o fim das altas (não tão altas assim, como visto) taxas de crescimento por acumulação de capital coincide com uma baixa capacidade de gerar inovação. Portanto, há uma tendência estrutural de redução da taxa de crescimento da renda per capita nos próximos anos. Fruto de imediatismos passados da sociedade como um todo, governos olhando seus projetos de poder e empresas concentradas nos ganhos de curto prazo, o país se vê hoje 
num descasamento perigoso de forças que podem se combinar perversamente. Do ponto de vista da mudança estrutural, o fim de um ciclo de acumulação de capital não coincide com o inicio de um ciclo de crescimento baseado em inovação. As diversas políticas industriais e de inovação dos últimos 20 anos não conseguiram mudar a realidade na intensidade que o país necessita. $\mathrm{O}$ país hoje corre desesperadamente em busca da inovação perdida, para manter-se na corrida das nações importantes no século XXI. O atraso do país neste aspecto pode ser visto na tabela 6 , a seguir.

E não há outra alternativa para o país senão revisar agressivamente sua política industrial-tecnológica-educacional. O problema da inovação no país não será resolvido apenas por sinais de mercado, uma vez que a alocação de recursos em pesquisa e desenvolvimento não é uma reação de curto prazo à incentivos do sistema de preço apenas. Ela envolve questões estratégicas que extrapolam a capacidade de coordenação de agentes tomando decisões individuais sinalizados por preços. As altas taxas de crescimento das patentes Coreanas, Chinesas, e Indianas poderiam servir de referência para reposicionar sua política industrialtecnológica doravante.

Não dá mais para continuar no mesmo ritmo tecnológico do passado, se o país quiser aumentar a renda per capita doravante.

Tabela 6 - Patentes concedidas pelo USPTO

\begin{tabular}{llrrr}
\hline Rank & Origin & 1998 & 2011 & Var $\%$ \\
\hline 1 & Japan & 32,118 & 48,256 & 50.2 \\
2 & Korea, South & 3,362 & 13,239 & 293.8 \\
3 & Germany & 9,582 & 12,968 & 35.3 \\
4 & Taiwan & 3,805 & 9,907 & 160.4 \\
5 & Canada & 3,536 & 5,754 & 62.7 \\
6 & France & 3,991 & 5,022 & 25.8 \\
7 & United Kingdom & 3,724 & 4,924 & 32.2 \\
8 & China, People's Republic of & 88 & 3,786 & $4,202.3$ \\
9 & Italy & 1,821 & 2,333 & 28.1 \\
10 & Australia & 830 & 2,213 & 166.6 \\
11 & Israel & 820 & 2,108 & 157.1 \\
12 & Netherlands & 1,382 & 2,049 & 48.3 \\
13 & Switzerland & 1,374 & 1,865 & 35.7 \\
14 & Sweden & 1,346 & 1,864 & 38.5 \\
15 & India & 94 & 1,259 & $1,239.4$ \\
16 & Finland & 629 & 1,023 & 62.6 \\
17 & Belgium & 755 & 958 & 26.9 \\
18 & Austria & 408 & 927 & 127.2 \\
19 & Denmark & 500 & 838 & 67.6 \\
20 & Singapore & 136 & 696 & 411.8 \\
21 & China, Hong Kong S.A.R. & 373 & 658 & 76.4 \\
22 & Spain & 308 & 565 & 83.4 \\
23 & Norway & 232 & 412 & 77.6 \\
24 & Ireland & 78 & 319 & 309.0 \\
25 & Russian Federation & 194 & 307 & 58.2 \\
26 & New Zealand & 145 & 255 & 75.9 \\
27 & Brazil & 88 & 254 & 188.6 \\
28 & South Africa & 132 & 144 & 9.1 \\
29 & Mexico & 77 & 117 & 51.9 \\
30 & Argentina & 51 & 10.9 \\
31 & Venezuela & 46 & 18 & -37.9 \\
\hline
\end{tabular}

Fonte: USPTO - U.S. PATENT AND TRADEMARK OFFICE, disponível em:

http://www.uspto.gov/web/offices/ac/ido/oeip/taf/cst_all.htm, acessado em 20/10/2012. 


\section{Referências}

Abramovitz, M. (1961), “The Nature and Significance of Kuznets Cycles.” Economic Development and Cultural Change, Vol 9(3), p. 225-248.

Alan Heston, Robert Summers and Bettina Aten, Penn World Table Version 7.1, Center for International Comparisons of Production, Income and Prices at the University of Pennsylvania, July 2012.

Alesina, A., and Perotti, R.; (1994). "The Political Economy of Growth: A Critical Survey of the Recent Literature", World Bank Economic Review Vol 8(3), p. $351-371$.

Ando, Albert and Modigliani, Franco; (1963). "The 'Life Cycle Hypothesis' of Saving” American Economic Review, March, Vol 51, p. 55-84.

Cole, H. L., L. E. Ohanian, A. Riascos and J. A. Schmitz Jr.; (2005). "Latin America in the Rearview Mirror", Journal of Monetary Economics, 52: 69-107.

Easterlin, R. A. (1968), Population, Labor Force and Long Swings in Economic Growth. New York: National Bureau of Economic Research.

Ellery Junrior, R. G.; (2009). Estratégias para o Crescimento da Economia Brasileira. In: Renaut Michel; Leonardo Carvalho. (Org.) Crescimento Econômico: Setor Externo e Inflação, Rio de Janeiro: IPEA, v. 1, p. 63-86.

Ellery Junrior, R. G.; (2011). Produtividade Total dos Fatores e Acumulação de Capitais no Brasil, mimeo, Departamento de Economia da Universidade de Brasília, ECO/UnB.

Fair, Ray C. and Dominguez, Kathryn M.; (1991). "Effects of the Changing U.S. Age Distribution on Macroeconomic Equations", The American Economic Review, Vol. 81 (5), Dec., p. 1276-1294;

Ferreira, P.C; Pessoa, S de A.; Veloso, F.A.; (2012). "On The Evolution of TFP in Latin América", Fundação Getulio Vargas, IBRE.

Harris, R. I. D. and Lau, I.; (1998). "Verdoorn's Law and Increasing Returns to Scale in the UK regions 1968-91: Some New Estimates Based on the Cointegration Approach", Oxford Economic Papers, Vol. 50, p. 201-219.

IPEA, (2011). "Emprego e oferta qualificada de mão de obra no Brasil: projeções para 2011”. Comunicados do IPEA, n. 89, Brasília - DF.

Kaldor, Nicholas (1966). Causes of the slow rate of economic growth of the United Kingdom: An inaugural lecture. Cambridge: Cambridge University Press.

Kaldor, Nicholas; (1975). "Economic Growth and Verdoorn's Law: A Comment on Mr. Rowthorn's Article”, Economic Journal, Vol 85, p. 891-896.

Kelley, Allen C. and Schmidt, Robert M.; (1995). Aggregate Population and Economic Growth Correlations: The Role of the Components of Demographic Change, Demography, Vol 32 (4), November, p. 543-555.

Mamgain, Vaishali; (1999). "Are the Kaldor-Verdoorn Laws Applicable in the Newly Industrializing Countires?", Review of Development Economics, Vol 3(3), p. 295309. 
Modigliani, Franco and Brumberg, Richard; (1954). "Utility Analysis and the Consumption Function: An Interpretation of Cross- Section Data" in K. K. Kurihara, ed., Post Keynesian Economics, New Bruns-wick, NJ: Rutgers University Press, p. 388-436.

Nassif, André; Feijó Carmem; Araújo, Eliane; (2012). "Structural Change and Economic Development: Is Brazil Catching-up or Falling Behind?", $9^{\text {th }}$ International Conference, Developments in Economic Theory and Policy, Bilbao, Spain, $28^{\text {th }}$ and $29^{\text {th }}$ of June, 2012.

Samuelson, P. (1962). Parable and Realism in Capital Theory: The Surrogate Production Function, Review of Economic Studies, Vol 29(3), p. 193-206.

Schumpeter, Joseph A.; (1934), A Theory of Economic Development, Harvard University Press, Cambridge: Massachusetts.

Sraffa, P.; (1960). Production of commodities by Means of Commodities: Prelude to a Critique of Economic Theory, Cambridge University Press.

Verdoorn, J. P.; (1949). "On the Factors Determining the Growth of Labor Productivity", in Pasinetti, L. Italian Economic Papers, Vol II, Oxford University Press, 1993. 